\title{
Numerical simulation of pounding damage to caisson under storm surge
}

\author{
CHEN Yu ${ }^{1, *}$
}

${ }^{1}$ Key Laboratory of Harbor \& Marine Structure Safety, Ministry of Communications, Tianjin Research Institute Water Transport Engineering M.O.T, Tianjin 300456, China

\begin{abstract}
In this paper, a new method for the numerical simulation of structural model is proposed, which is employed to analyze the pounding response of caissons subjected to storm surge loads. According to the new method, the simulation process is divided into two steps. Firstly, the wave propagation caused by storm surge is simulated by the wave-generating tool of Flow-3D, and recording the wave force time history on the caisson. Secondly, a refined 3D finite element model of caisson is established, and the wave force load is applied on the caisson according to the measured data in the first step for further analysis of structural pounding response using the explicit solver of LSDYNA. The whole simulation of pounding response of a caisson caused by "Sha Lijia" typhoon is carried out. The results show that the different wave direction results in the different angle caisson collisions, which will lead to different failure mode of caisson, and when the angle of 60 between wave direction and front/back wall is simulated, the numerical pounding failure mode is consistent with the situation.
\end{abstract}

\section{Introduction}

As the economic development in China, many largescale offshore structures including wharf, artificial islands are growing rapidly in recent years. The Eastern and Southern Coasts in China are often attacked by typhoon, which leads storm surge attacking the offshore structures damage. In October 2016, the constructing caisson suffered pounding damage under the storm surge caused by "Sha Lijia" typhoon in southern China. Fig.1 illustrates the cracks occur in the middle and side caisson walls after "Sha Lijia" typhoon, and the pounding location of the concrete suffers serious damage.

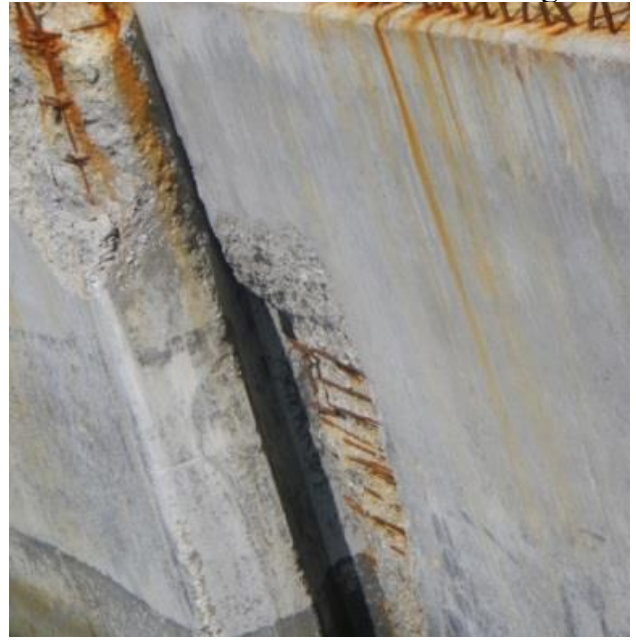

(a)

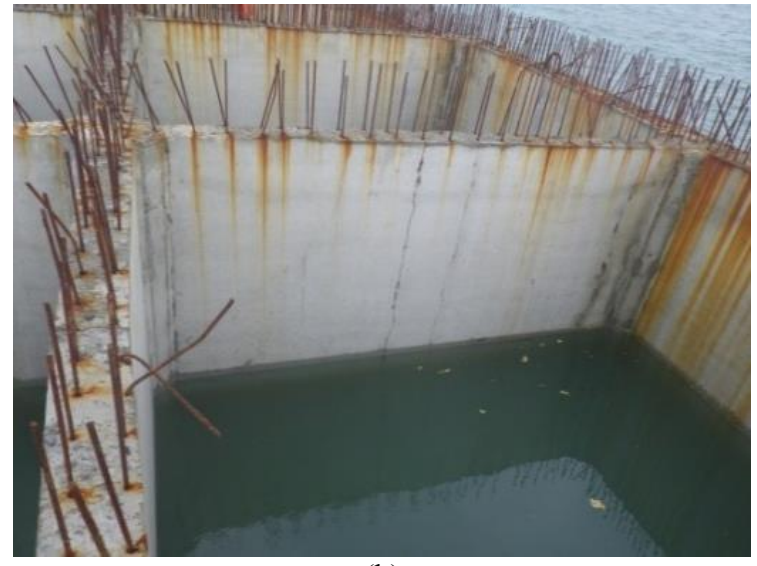

(b)

Fig.1. Damaged caisson.

In order to explain the reason of the cracks, it needs to simulate the pounding mechanical behavior between the caissons under the storm surge. For the numerical simulation, firstly, it should get the wave force on the caisson. Morison Equation [1] or Radiation Wave Theory [2, 3] can solve wave force on the cylinder, but they are not suitable for the caisson. The literature [4] gives the static wave force distribution of the caisson, which can't be used to the pounding simulation. Because pounding simulation is based on the time depending, the wave force time history needs. Secondly, a detailed 3D finite element model of the caisson should be established to accurately simulate the pounding effects including high frequency and short duration on the caisson $[5,6]$. Traditional simulation technology often needs to calculate the dynamic response of structures merging the

\footnotetext{
* Corresponding author: tjucy@tju.edu.cn
} 
wave and the structure model. The complexity and large calculating quantity made the numerical simulation impossible.

In this study, a new two-step method for the numerical simulation of pounding damage between two caissons under storm surge is proposed. The first step, fluid grids are established based on the FAVOR grid technology using high-precision fluid Flow software Flow-3D. The Continuity Equation and Navier-Stokes Equation are taken as the control equations, the coupling equations of pressure and velocity are solved by GMRES (Generalized Minimum RESidual) implicit algorithm, and then the wave force time history on the caisson structure can be calculated. The second step, a 3D finite element model of the caisson is established using LSDYNA [7]. The time history of wave force obtained in the first step is input to the numerical simulation to calculate the pounding damage and failure process of the caissons using the LS-DYNA explicit solver. The method was applied to the pounding analysis of the collision under storm surge caused by "Sha Lijia" typhoon, and the relations between the wave direction and failure mode of the caisson is discussed.

\section{Damage analysis of the caisson caused by "Sha Lijia" typhoon}

\subsection{Caisson details}

Fig. 2 shows the elevation view of the caisson. In order to clearly describe the caisson walls, each intersection point of two caisson walls is numbered. The front (C-D) and back (A-B) walls have the thickness of $400 \mathrm{~mm}$ and $350 \mathrm{~mm}$ respectively. The side (A-D, B-C) walls have the thickness of $300 \mathrm{~mm}$. All of the interior (h-f, e-g) wall thickness are $250 \mathrm{~mm}$. The compressive strength of the concrete used for the caisson is $40 \mathrm{MPa}$. The steel reinforcement has an elasticity modulus of 206GPa and a yield strength of $400 \mathrm{MPa}$, and the steel reinforcement ratio is $0.8 \%$. The caissons are placed side by side on the foundation, and a $200 \mathrm{~mm}$ gap is introduced between the caissons.
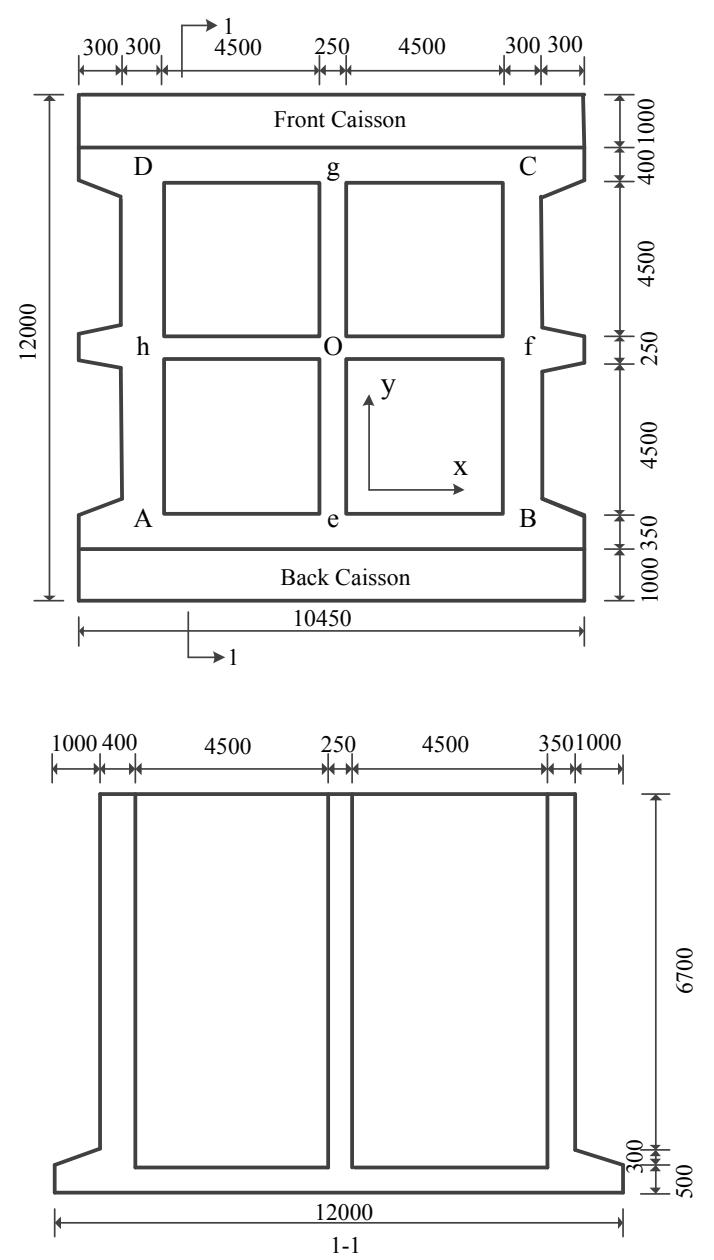

Fig.2. Caisson sizes (unit: mm).

\subsection{Wave force on caisson}

High-precision fluid Flow software Flow-3D [8] provides users solving the wave force on the caisson in three dimensions. In this study, three cases including the angles of $0,30,60$ between wave direction and $\mathrm{x}$ direction. The $\mathrm{x}$ direction is defined as be parallel to the front/back wall. In the case of angle of 0 as an example, three-dimensional numerical flume model is described. As shown on Fig. 3, the water channel has $12 \mathrm{~m}$ high, 120 $\mathrm{m}$ long and $10 \mathrm{~m}$ wide, and the angle between the wave direction and the front/back wall in the water channel is 0. Fig. 4 shows the boundary conditions of the water channel. The front of the water channel is set to Wave boundary, the back is set to the Specified pressure boundary, the bottom is set to Wall boundary, and the rests are set to Symmetry boundary. The initial velocity of the water is set as zero, and the hydrostatic pressure along the $\mathrm{z}$ axis is set. 


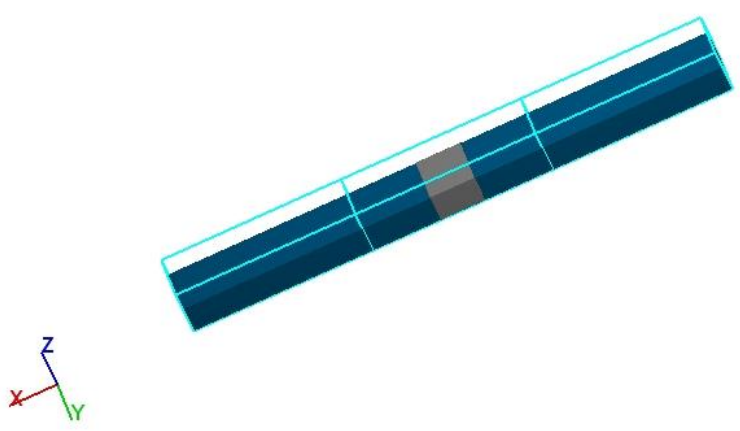

Fig.3. 3D numerical model of sink-structure.

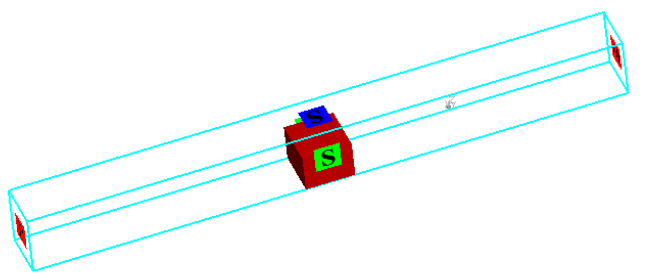<smiles>[Z]C([Y])[CH]</smiles>

Fig.4. Sketch of boundary conditions.

According to meteorological data, the wind force of the "Sha Lijia" typhoon is 14. The significant wave height of $5.0 \mathrm{~m}$ and the average period of $8.8 \mathrm{~s}$ can be obtained corresponding to the 14 level of wind force in the literature [9]. According to the design data, the water depth is $7.35 \mathrm{~m}$. The water depth, significant wave height and the average period are input to the Flow-3D wave system, the wave generation can be achieved as shown in Fig.5.

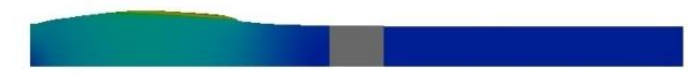

$\sum_{x}^{2}$

Fig.5. Wave generation.

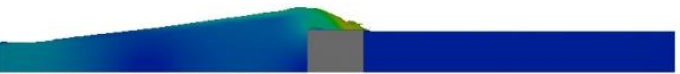

Fig.6. Overtopping phenomenon.

Computation time is taken as 5 times of wave period (i.e., 45.5 s). Overtopping phenomenon occur after the wave acts on the caisson (see Fig.6). The wave force time history can be achieved by recording the wave pressure on the surface of the caisson. Similarly, the three-dimensional numerical flume models corresponding to the angles of 30, 60 between the wave direction and $\mathrm{x}$ direction are established. As shown on Fig.7, the maximum force is $2710 \mathrm{kN}, 3427 \mathrm{kN}$ and $3613 \mathrm{kN}$ corresponding to the angles of $0,30,60$ respectively, and they occur in the first wave. As overtopping phenomenon occurs, the wave force is irregular after first wave.

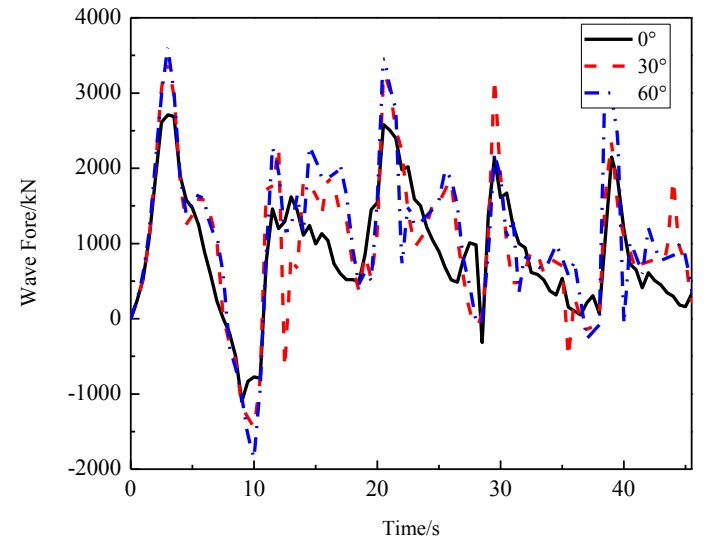

Fig.7. Wave force time histories with different angles between wave direction and $\mathrm{x}$ direction.

\subsection{Finite Element Model}

Two finite element models of 3D solid elements are established to simulate the pounding responses of the caisson using LS-DYNA, and the rigid foundation is set to simulate the rubble-bedding, as shown on Fig.8. In the finite element models, solid elements are used to simulate the behavior of concrete. The Belytschko beam elements are applied to simulate the mechanical properties of steel reinforcements. A perfect bond assumption is incorporated to model the connections between the steel reinforcements and the concrete. The 3D finite element model for the caisson is depicted in Fig.9. In order to improve calculative efficiency, the rigid model is used to simulate the concrete and steel reinforcements for the caisson B (see Fig.8), and the concrete damage model (MAT_CONCRETE_DAMAGE_REL3) and the elasticplastic model (MAT_PLASTIC_KINEMATIC) are used to simulate the other caisson $\overline{\mathrm{A}}$, respectively. Table 1 tabulates the material properties adopted in this study.

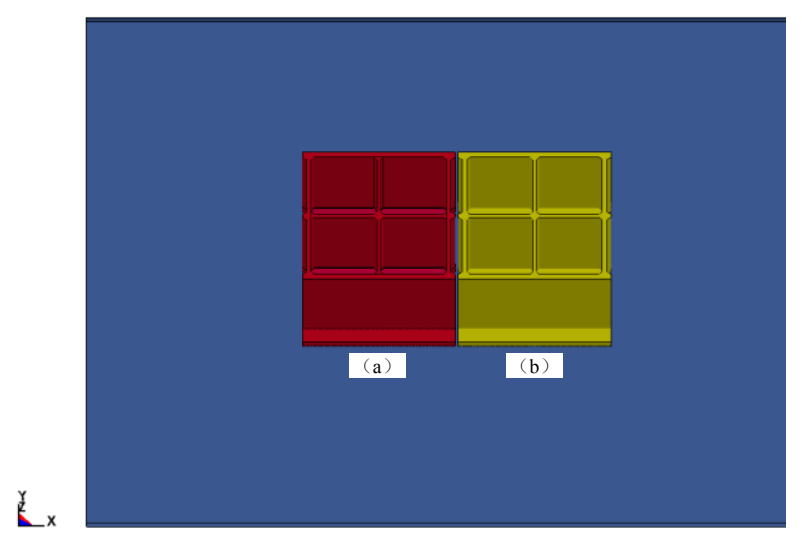

Fig.8. Model of caissons. 


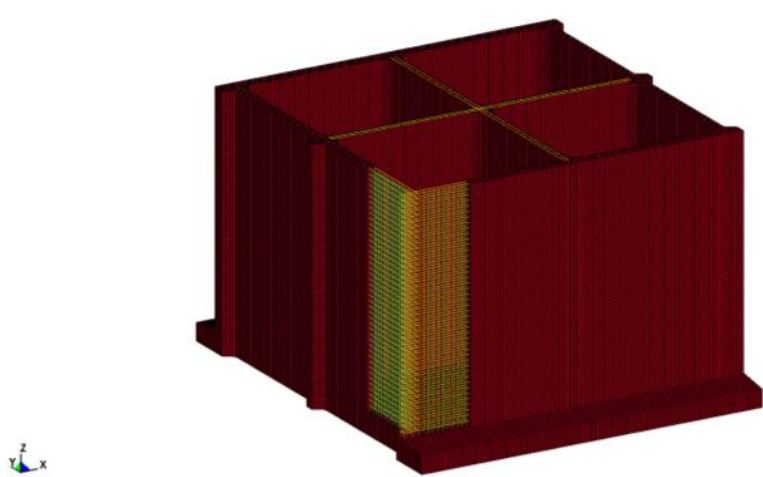

Fig.9. 3D finite element model of caisson.

The strengths of the structural materials are strain rate dependent as their dynamic properties can be enhanced significantly when subjected to impact loads $[10,11]$. Current study employs the dynamic increase factor $(D I F)$, a ratio of the dynamic to static strength against strain rate to account for the material strength enhancement with strain rate effect.The bilinear relationship developed by CEB code [12] and Malvar and Ross [13] are applied in this study for the concrete strength enhancement. In tension, the DIF of the tensile strength is given by the following equations [13]:

$$
\begin{aligned}
& T D I F=\frac{f_{t d}}{f_{t s}}=\left(\frac{\&}{\&} \frac{\&}{\& s}\right)^{\delta} \quad \& \leq 1 s^{-1} \\
& T D I F=\frac{f_{t d}}{f_{t s}}=\beta\left(\frac{\& d}{\& t s}\right)^{1 / 3} \quad \&>1 s^{-1}
\end{aligned}
$$

where $f_{t d}$ is the dynamic tensile strength at strain rate $\&, f_{t s}$ is the static tensile strength at $\&_{t s}^{\&}=10^{-6} s^{-1}$, $\log \beta=6 \delta-2, \delta=1 /\left(1+8 f_{c}^{\prime} / f_{c o}^{\prime}\right), f_{c o}^{\prime}=10 \mathrm{MPa}, f_{c}^{\prime}$ is the static uniaxial compressive strength of concrete.

In compression, the equations are given by $\mathrm{CEB}$ code as follows [12]:

$$
\begin{array}{ll}
C D I F=\frac{f_{c d}}{f_{c s}}=\left(\frac{\& d}{\& d}\right)^{1.026 \alpha} & \& \leq 30 s^{-1} \\
C D I F=\frac{f_{c d}}{f_{c s}}=\gamma(\&)^{1 / 3} & \&>30 s^{-1}
\end{array}
$$

where $f_{c d}$ is the dynamic compressive strength at strain rate \& $f_{c s}$ is the static compressive strength at $\underset{c s}{\&}=30$ $\times 10^{-6} s^{-1}, \log \gamma=6.156 \alpha-0.49, \alpha=\left(5+3 f_{c u} / 4\right)^{-1}$, and $f_{c u}$ is the static cube strength.

The K\&C model [14] is adopted to determine the $D I F$ for the reinforcements which is given as

$$
\begin{gathered}
D I F=\left(\frac{\&}{10^{-4}}\right)^{\alpha} \\
\alpha=0.074-0.040 f_{y} / 414
\end{gathered}
$$

where $f_{y}$ is the steel yield strength in $\mathrm{MPa}$.

The penalty method is used to model the contact interfaces between different elements. The contact algorithm,

i.e., CONTACT_AUTOMATIC_SURFACE_TO_SURFAC $\mathrm{E}$ is used to simulate the contact between the caissons

\begin{tabular}{|c|c|c|c|}
\hline $\begin{array}{c}\text { Materi } \\
\text { al }\end{array}$ & Material model & Parameters & Value \\
\hline \multirow{2}{*}{$\begin{array}{c}\text { Concret } \\
\mathrm{e}\end{array}$} & \multirow{2}{*}{$\begin{array}{c}\text { MAT_CONCRET } \\
\text { E_DAMAGE_REL } \\
3\end{array}$} & Mass density & $\begin{array}{c}2500 \mathrm{k} \\
\mathrm{g} / \mathrm{m} 3\end{array}$ \\
\hline & & $\begin{array}{c}\text { Compressive } \\
\text { strength }\end{array}$ & $40 \mathrm{MPa}$ \\
\hline \multirow{5}{*}{$\begin{array}{l}\text { Steel } \\
\text { reinforc } \\
\text { ements }\end{array}$} & \multirow{5}{*}{$\begin{array}{l}\text { MAT_PLASTIC } \\
\text { KINEMATIC }\end{array}$} & Mass density & $\begin{array}{l}7850 \mathrm{k} \\
\mathrm{g} / \mathrm{m} 3\end{array}$ \\
\hline & & $\begin{array}{l}\text { Young's } \\
\text { modulus }\end{array}$ & $\begin{array}{c}206 \mathrm{GP} \\
\mathrm{a}\end{array}$ \\
\hline & & $\begin{array}{c}\text { Poisson's } \\
\text { ratio } \\
\end{array}$ & 0.3 \\
\hline & & Yield strength & $\begin{array}{c}400 \mathrm{M} \\
\mathrm{Pa}\end{array}$ \\
\hline & & $\begin{array}{c}\text { Tangent } \\
\text { modulus }\end{array}$ & $\begin{array}{c}20.6 \mathrm{G} \\
\mathrm{Pa}\end{array}$ \\
\hline
\end{tabular}
and the contact between the caisson and the foundation. By using this contact algorithm Coulomb friction needs to be specified, which are set to be 0.5 [15] and 0.6 [16] corresponding to the two contacts respectively.

Table 1. Material Parameters.

\subsection{Input wave force time history}

The three time histories of wave force obtained in the Section 2 corresponding to three cases of the angle of 0 , 30, 60 are written to the model file in LS-DYNA. The wave forces are applied on the centre of gravity of the caisson $\mathrm{B}$, and the caisson $\mathrm{B}$ move to collide with caisson A.

\section{NUMERICAL RESULTS}

The pounding damage of the caisson under storm surge is simulated in three cases using proposed method. Fig. 10 shows the caisson damage modes in three cases including the angles of $0,30,60$ between the wave direction and $\mathrm{x}$ direction. As shown on Fig.10, the pounding damage modes and extents of damage are not the same in the three cases. In the case of the angle of 0 , Fig.10a shows that the side caisson walls (A-D, B-C) suffer serious damage, and have crack damage in the middle. The interior caisson walls $(\mathrm{O}-\mathrm{e}, \mathrm{O}-\mathrm{g})$ suffer serious damage, and interior walls $(\mathrm{O}-\mathrm{f}, \mathrm{O}-\mathrm{h})$ keep well. In the case of the angle of 30 , Fig. $10 \mathrm{~b}$ shows that the side caisson walls (A-D, B-C) suffer serious damage. All of the interior caisson walls (O-e, O-g, O-f, O-h) suffer damage, and the damage extent of the walls $(\mathrm{O}-\mathrm{e}, \mathrm{O}-\mathrm{g})$ is relatively minor comparing to the walls $(\mathrm{O}-\mathrm{f}, \mathrm{O}-\mathrm{h})$. In the case of the angle of 60 , Fig. 10c shows that all of the front, back, side caisson walls (A-D, B-C, A-B, C-D) keep well, and the damage modes of the interior caisson walls are similar to the cases of the angle of 30 . The damage extent of the interior walls $(\mathrm{O}-\mathrm{e}, \mathrm{O}-\mathrm{g})$ is relatively minor comparing to the case of the angle of 30 , and the damage extent of the interior walls $(\mathrm{O}-\mathrm{f}, \mathrm{O}-\mathrm{h})$ is relatively serious comparing to the cases of the angles of 0,30 . This result occurs because the inertia force in $\mathrm{x}$ direction for the interior walls $(\mathrm{O}-\mathrm{e}, \mathrm{O}-\mathrm{g})$ is large if the angle of the collision between caisson $\mathrm{B}$ and caisson $\mathrm{A}$ is small result from the small angle between the wave and $\mathrm{x}$ direction. At the same time, the inertia force in $y$ 
direction for the interior walls (O-f, O-h) is small. The large inertia force in $\mathrm{x}$ direction causes the damage in the middle and end of the wall $(\mathrm{O}-\mathrm{e}, \mathrm{O}-\mathrm{g})$. It is observed that the damage mode of the caisson in the case of the angle of 60 is consistent with the actual situation as shown in Section 2.1.

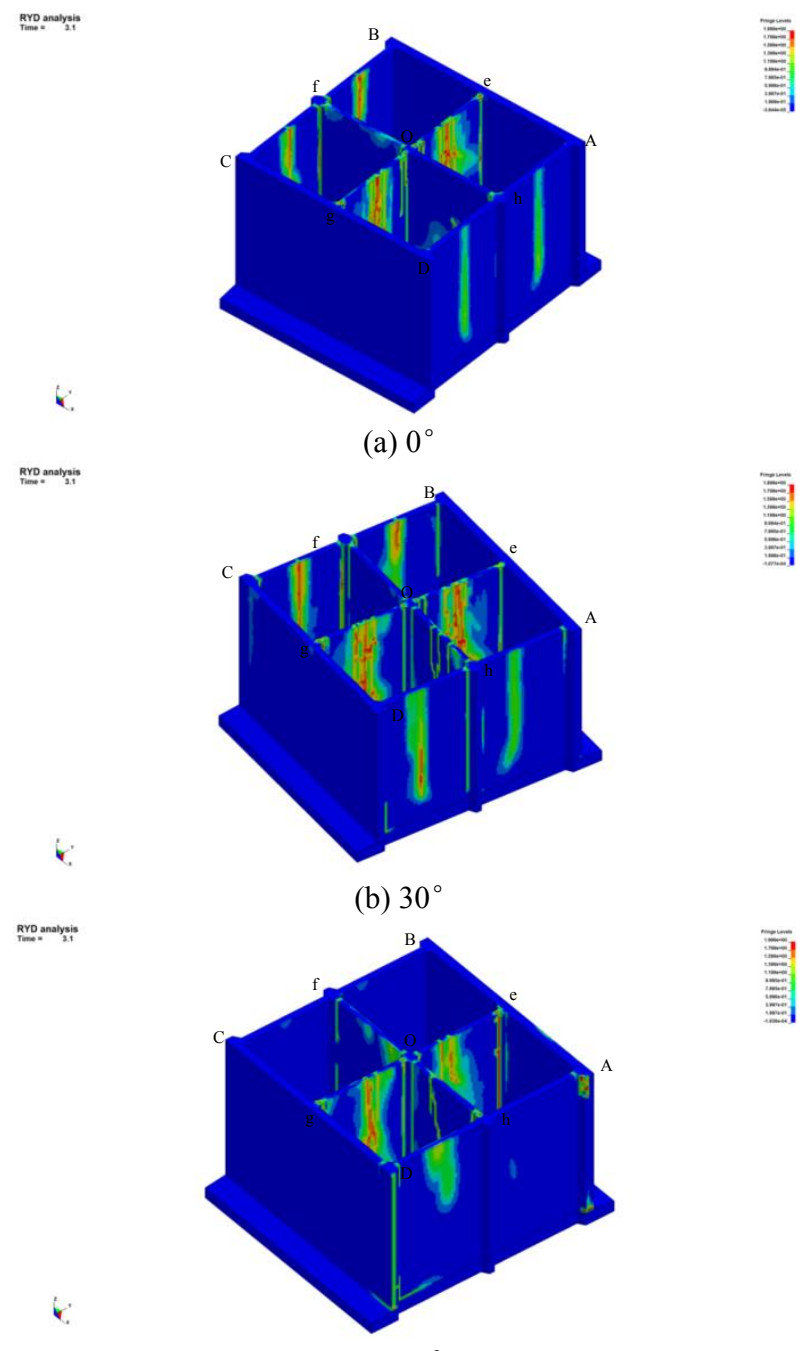

(c) $60^{\circ}$

Fig.10. Pounding failure mode of caisson under the different pounding angles between caisson B and caisson A.

\section{CONCLUSION}

A new method for the numerical simulation of structural model in two steps is proposed, which is employed to analyze the pounding response of caissons subjected to storm surge loads caused by "Sha Lijia" typhoon. The following conclusions are obtained.

(1)The different wave direction results in the different angle caisson collisions, and it will lead to different failure mode of caisson.

(2)When the angle of 60 between wave direction and front/back wall is simulated, the numerical pounding failure mode is consistent with the situation. The pounding failure mode is that all of the front, back and side caisson walls keep well, and the interior walls suffer damage in different extent.

\section{ACKNOWLEDGMENT}

The authors gratefully acknowledge the support for this research from the Central Public Welfare Science Foundation under Grant Nos. TKS170109 and TKS150204.

\section{REFERENCES}

1. Terro M J, Abdel-Rohman M, Terro M J. Wave induced forces in offshore structures using linear and nonlinear forms of morison's equation [J]. Journal of Vibration \& Control, 2007, 13(2): 139157.

2. Bao W G, Fujihashi K, Kinoshita T. Interaction of a submerged elliptic plate with waves [J]. Journal of Hydrodynamics, 2010, 22(5): 77-82.

3. Li Zhongxian, Huang Xin. Dynamic responses of bridges in deep water under combined earthquake and wave actions [J]. China Civil Engineering Journal, 2012, (11): 134-140.

4. JTS145-2015, Code of Hydrology for Harbour and Waterway [S]. Beijing: People's Communication Publishing Company, 2015.

5. Anxin Guo, Zhongjun Li, Hui Li. Point-to-Surface Pounding of Highway Bridges with Deck Rotation Subjected to Bi-Directional Earthquake Excitations[J]. Journal of Earthquake Engineering, 2011, 15(2): 274-302.

6. Bi K, Hao H. Numerical simulation of pounding damage to bridge structures under spatially varying ground motions[J]. Engineering Structures, 2013, 46(1): 62-76.

7. LS-DYNA. LS-DYNA user manual. Livermore Software Technology Corporation; 2007.

8. Zhang Ting. Three-dimensional numerical simulation of waves and its application [D]. Tianjin: Tianjin University, 2009.

9. Fang Zhongsheng, Jin Chengyi. Statistical analysis on wave height, wind speed and other parameters due to tropical cyclones in the northwest pacific area [J]. Journal of ship mechanics, 2003, 7(5): 1-10. (in Chinese)

10. Shi Yanchao, Li Zhongxian, Hao Hong. Numerical analysis of progressive collapse of reinforced concrete frame under blast loading [J]. Journal of Pla University of Science and Technology, 2007, 8(6): 652-658.

11. Bischoff P H, Perry S H. Compressive behaviour of concrete at high strain rates[J]. Materials and Structures, 1991, 24(6): 425-450.

12. Comite Euro-International du Beton. Concrete structures under impact and impulsive loading. CEB Bulletin 187. Switzerland: Federal Institute ofTechnology Lausanne; 1990.

13. Malvar L J, Ross C A. A Review of Strain Rate Effects for Concrete in Tension[J]. Aci Materials Journal, 1998, 95(6):735-739. 
14. Malvar L J. Review of static and dynamic properties of steel reinforcing bars[J]. Aci Materials Journal, 1998, 95(5):609-616.

15. JTS167-2-2009, Design and Construction Code for Gravity Quay [S]. Beijing: People's Communication Publishing Company, 2009.

16. Bi K, Hao H. Numerical simulation of pounding damage to bridge structures under spatially varying ground motions $[\mathrm{J}]$. Engineering Structures, 2013, 46(1): 62-76. 